\section{Forced marriage: implications for mental health and intellectual disability services}

\author{
Bushra Rauf, Nadia Saleem, Rachael Clawson, Mandy Sanghera \& Geoff Marston
}

\section{ARTICLE}

\begin{abstract}
SUMMARY
There has been growing media and political awareness of forced marriage in recent years, and individuals in England, Wales and Northern Ireland are now protected by the Forced Marriage (Civil Protection) Act 2007. Victims of forced marriage can experience significant abuse, which may lead to mental health problems. People with severe mental illness or intellectual disability may be at increased risk of forced marriage and more vulnerable to its negative consequences. We review the current literature on forced marriage, focusing on the way it might affect these two groups, touch on its potential mental health consequences and give practical examples of how to manage situations in clinical practice.
\end{abstract}

\section{DECLARATION OF INTEREST}

R.C., in conjunction with the Ann Craft Trust, conducts research and training on forced marriage, with financial support from the Home Office/ Foreign and Commonwealth Office Forced Marriage Unit Domestic Programme Fund. M.S. has been a trustee for Voice UK and has done commissioned work on forced marriage.

\section{'A forced marriage is a marriage in which one or both spouses do not (or, in the case of some adults with learning or physical disabilities, cannot) consent to the marriage and duress is involved. Duress can include physical, psychological, financial, sexual and emotional pressure.' (Stobart 2009: p. 8)}

Forced marriage can be seen as an abuse of human rights, a form of domestic abuse and a form of violence against the person, both male and female. When it involves people with a disability or severe mental illness it is an abuse against a vulnerable adult. If it affects children and young people, it is child abuse.

Forced marriage is distinct from arranged marriage, where families take a leading role in choosing the person to be wed, but the decision to accept the arrangement remains with the prospective spouses. An arranged marriage when one or both spouses lack the ability to consent to it, for whatever reason, would constitute a forced marriage. Khanum (2008) argued that the definition of forced marriage should be broadened to include 'false marriages', where 'someone has been tricked into giving consent through false information about the other party (e.g. the existence of previous marriages)'. One could argue that the presence of an intellectual disability (commonly known as a learning disability in UK health services) or severe mental illness should be disclosed.

The concept of 'duress' in Stobart's definition may not always be applicable, particularly in certain groups. For example, people with an intellectual disability may be more acquiescent, wanting to please their family or do what their siblings have done, trusting their family without understanding potential implications. Families may also 'coach' spouses to give the impression of understanding when questioned by, for example, professionals undertaking an assessment of capacity.

\section{Epidemiology of forced marriage}

It is difficult to obtain accurate information about the extent of forced marriage and data available are likely to grossly underestimate numbers. The Forced Marriage Unit, a joint initiative between the UK's Foreign and Commonwealth Office and Home Office, provides advice and practical support regarding forced marriages both in the UK and abroad. In 2010, the unit's expertise was sought on 1735 occasions (Singh 2011). Karma Nirvana (a specialist Black and minority ethnic non-governmental organisation) dealt with over 13000 callers between April 2008 and the end of January 2011 (Singh 2011), and Kazimirski et al (2009) estimated a national UK prevalence of 5000-8000 cases of actual or threatened forced marriage in 2008. A survey carried out by the charity Women's Aid (2008) in 2006-2007 found that 870 women in refuge accommodation $(5 \%$ of the total) were fleeing forced marriages.

A study involving women with intellectual disability who were either married, pregnant or parents and living in the east London borough of Tower Hamlets found that all of the Bangladeshi
Bushra Rauf and Nadia Saleem are specialist registrars in Coventry and Warwickshire Partnership NHS Trust. Rachael Clawson is a lecturer in social work, Centre for Social Work, School of Sociology and Social Policy, University of Nottingham. Mandy Sanghera is an independent campaigner for the rights of people with intellectual disability. Geoff Marston is a consultant psychiatrist in Coventry and Warwickshire Partnership NHS Trust, UK.

Correspondence Rachael Clawson, School of Sociology and Social Policy, Room B9 Law and Social Sciences Building, University Park, University of Nottingham, Nottingham NG7 2RD, UK. Email: rachael.clawson@nottingham.ac.uk 
women were married, compared with less than half of the others (O'Hara 2003). Many of the women had questionable capacity to consent to marriage, implying that a number may have been within a forced marriage situation. Among the 1735 contacts with the Forced Marriage Unit in 2010 (Singh 2011), 70 cases involved people with disabilities (50 with intellectual disability, 17 with physical disability and 3 with both). No specific data were collected about the number of cases involving people with severe mental illness.

The majority of forced marriages reported in the UK involve South Asian families. However, there are instances involving East Asian, Middle Eastern, gypsy/traveller, European and African communities too (Gangoli 2006; Hester 2007). Most victims who contacted the Forced Marriage Unit in 2010 were women $(86 \%)$, but there should remain significant concern about male victims, as reported numbers have risen by $65 \%$ (from 134 victims to 220 ) between 2008 and 2009 (Singh 2011).

A study of 289 front-line practitioners from a range of agencies, including healthcare, police, Social Services and education (Clawson 2010), found that:

- 71 cases of forced marriage were reported in people with intellectual disability, most being aged 18-25 years, with the youngest being 14;

- the proportion of males and females was more equal than in the general population $(38 \%$ male, $45 \%$ female; $17 \%$ not reported) and most lived with their families, who were usually the instigators of marriage;

- $90 \%$ of the forced marriages were reported by a third party;

- almost 70\% either lacked capacity or had capacity questioned with regard to consenting to marriage;

- most marriages (80\%) took place outside the UK.

Children may be especially vulnerable to forced marriages, with a third of cases handled by the Forced Marriage Unit in 2010 related to people under the age of 18. Although child marriage is a worldwide phenomenon, it is most prevalent in African and South East Asian communities, so it may be more likely to affect these communities in the UK (Singh 2011). All psychiatric professionals, particularly those working in child and adolescent mental health services, should be especially aware of signs of forced marriage (see below) when seeing children within at-risk ethnic groups.

There are sporadic case reports in the psychiatric press regarding the marriage of vulnerable people with severe mental illness who lack capacity. Peisah et al (2008) presented two cases of older people with mental illness: an 87-year-old man who married a carer 50 years his junior while hypomanic; and an 82-year-old woman with moderate dementia who married her boarder, the marriage subsequently being found void by Australian courts. Sillifant et al (1995) questioned the legal issues involved in postponing, against her spouses wishes, the marriage of an incapacitous young woman who had psychotic depression and was an in-patient at the time of the planned wedding. Owing to the lack of capacity in each case, all of these situations could be considered as involving forced marriage, although the motives for each may have been different.

\section{What are the motives behind forcing someone into marriage?}

Clawson (2010) points out that the motivations behind forced marriage vary and include what families would see as 'positive' reasons. Families of people with severe mental illness or intellectual disability may not see that the marriage they are organising is 'forced' because of cultural beliefs or lack of awareness of human rights in the UK. They may see themselves as protecting their children's future care or financial requirements, building stronger family ties, upholding long-standing commitments, or protecting or preserving perceived cultural/religious ideals and traditions (often misguided). Although it is important to understand a family's motives, these should never be accepted as justification for their actions. Every major faith has condemned the concept of forced marriage being justified on religious grounds, with freely given consent being a prerequisite of Christian, Jewish, Hindu, Muslim and Sikh marriages (Gangoli 2006; Ratnaike 2007).

More negative motivating factors include controlling unwanted behaviour and sexuality (e.g. perceived promiscuity, being gay/lesbian), protecting 'family honour', ensuring that property and wealth remain within a family, preventing 'unsuitable' relationships (e.g. outside of ethnic, cultural, religious or class groups), assisting residence and citizenship claims, or by-passing certain immigration and asylum rules (Hester 2007).

For people with intellectual disability, other motivating factors may be involved (Samuel 2008; Clawson 2010):

- the family may be looking to obtain a long-term care option or financial security for their child

- they may see marriage as a 'rite of passage' that should be available for all

- they may worry that younger children will be seen as undesirable if an older sibling with an intellectual disability is not already married

- the marriage may be seen as the only or right option, or both

- obtaining physical assistance for ageing parents 
- believing that the marriage will somehow 'cure' disability.

Some families mistrust social care and healthcare systems, preferring to look after intellectually disabled relatives themselves. There is some evidence that women with intellectual disability are forced to marry 'disgraced' men who are regarded as 'unsuitable' partners for others. This highlights the low worth placed on many women who have an intellectual disability.

Many of these issues may be equally applicable to people with severe mental illness who lack capacity. Conversely, in some situations families might seek a label of mental illness to explain a person's refusal to consent to a proposed (possibly forced) marriage, but to date little has been written about this group.

\section{Capacity and consent}

It is important to remember that, according to the Mental Capacity Act 2005 for England and Wales, the court and/or any individual (including a parent) cannot in any circumstances give consent to marriage on behalf of an adult who lacks the capacity to give his/her own consent. Consequently, any marriage ceremony that involves an incapacitous person must be viewed as forced, regardless of why it took place.

The Mental Capacity Act 2005 offers a useful framework around which to assess decision-specific capacity at a given time. However, assessing capacity to consent to marriage is complex, involving a number of separate capacity assessments in different areas. Box 1 highlights some areas needing further exploration. These assessments are not a comprehensive list and may need to involve a number of professionals.

Where there are communication problems it might be helpful to use pictures and easy-to-read literature or to enlist the help of a speech and language therapist. Clinicians should be aware of possible acquiescence shown by people with intellectual disability when answering questions; likewise, care should be taken to avoid relatives answering questions on a person's behalf, or acting as a potentially biased translator. Murphy (2003) found that sex education made a significant difference to the knowledge and understanding of sexual relationships and capacity to consent.Various resources are available to help such assessments (e.g. Health Scotland 2008; Kelly 2009).

\section{Legal aspects of forced marriage}

On 10 October 2011, UK Prime Minister David Cameron included issues of forced marriage in his speech on immigration and deemed it 'little more than slavery' and 'completely wrong' (Number
B0X 1 Exploring capacity

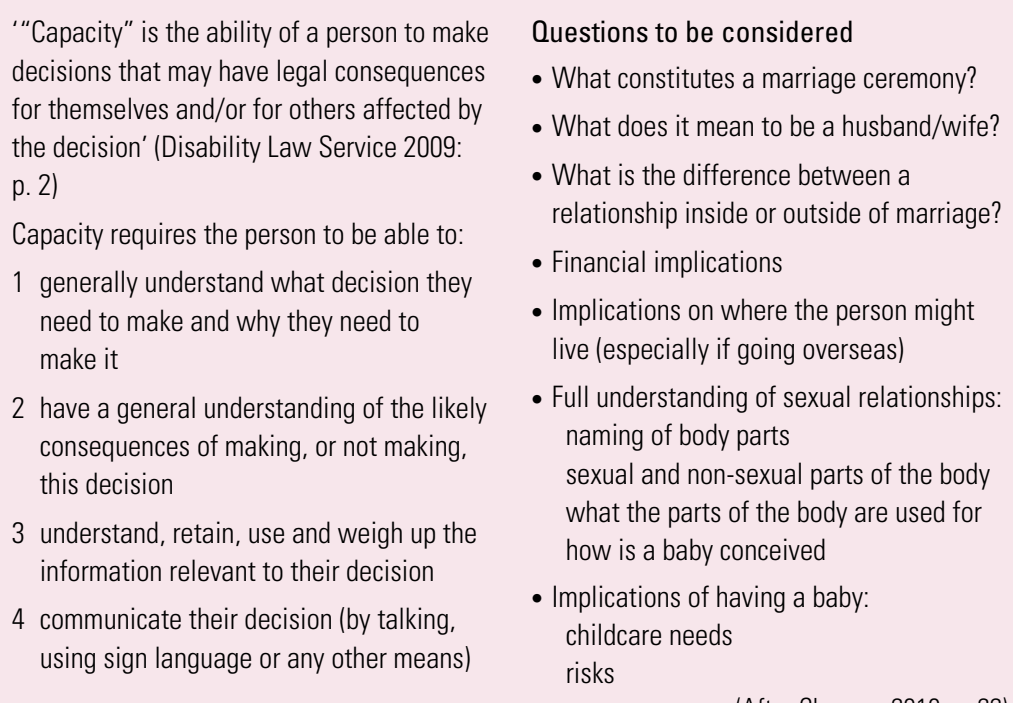

(After Clawson 2010: p. 22)

10 2009). The Home Secretary, Theresa May, announced on 12 December 2011 that the public would be consulted on making 'forcing someone to marry' a criminal offence (Home Office 2011). Following the consultation, the government announced on 8 June 2012 its intention to introduce new legislation making forcing someone to marry a criminal offence punishable by a prison sentence. The timetable for creating the new legislation is not yet clear. The question of whether or not making 'forcing someone to marry' a criminal offence will help victims is one that is much debated (Gill 2011). There are a number of arguments for and against (Box 2).

At the time of writing, 'forcing someone to marry' is not in itself a criminal offence in the UK; however, within a forced marriage, various offences may be

\section{BOX 2 Arguments for and against making 'forcing someone to marry' a} criminal offence

\section{For}

- Sends out a strong message that forced marriage will not be tolerated

- Criminalises perpetrators who could be subject to ongoing supervision post sentencing

- Helps to clarify the position for many practitioners

\section{Against}

- Legislation already exists but is not consistently applied

- Lack of understanding of current legislation among professionals

- Could discourage victim reporting

- Could prevent reconciliation with family

- Could be seen to 'deal' with the issue of forced marriage, without addressing longer-term matters such as support, education/awareness-raising in communities and professionals 
committed. Examples given in the Sexual Offences Act 2003 include inciting or facilitating a person without capacity to engage in sexual activity, and the spouse may not appreciate that they are committing an offence in this situation. Women may be subject to repeated rape, often until they become pregnant. It should also be pointed out that young people under the age of 16 cannot legally consent to a sexual relationship.

For example, in $K C \& N N C{ }_{v}$ City of Westminster v IC [2008], a young man with autism, severe intellectual disability and who lacked capacity was married over the telephone to a woman living in Bangladesh who had no intellectual disability. The Court of Appeal ruled that this marriage, although recognised in Bangladesh and in Sharia law, was not entitled to recognition under UK law. The Court ruled further that consummating the marriage would be tantamount to rape or indecent assault.

The Forced Marriage (Civil Protection) Act 2007 enables courts in England, Wales and Northern Ireland to issue protection orders with a range of conditions, the breaching of which can result in prosecution and a custodial sentence for those responsible. In Scotland, the Forced Marriage etc. (Protection and Jurisdiction) (Scotland) Act 2011 offers similar protection from forced marriage.

Where there are concerns, local authorities can apply to the Court of Protection for declarations and orders to protect vulnerable individuals. The Court can operate alongside both the Forced Marriage (Civil Protection) Act 2007 and Mental Capacity Act 2005. The latter gives the Court decision-making powers over property, affairs, healthcare and personal welfare for adults who lack capacity. Under the former, the Court can act to restrain family members from arranging a marriage or to prevent a person being taken overseas for the purpose of marriage. It may also assist attempts to repatriate those taken out of the country and forced into marriage.

It is important that all clinicians working in the field of mental health and intellectual disability are aware of these legal aspects of forced marriage so they can better support service users and offer appropriate information and assessments to courts, should they be required to submit reports or act as an expert witness. Guidance on legal aspects of forced marriage has been published by the Ministry of Justice (www.justice.gov.uk/protectingthe-vulnerable/forced-marriage). Key legislation is summarised in Box 3.

\section{Consequences of forced marriage}

For many victims, isolation and the feeling that there is no one to trust or speak to about their
B0X 3 Key legislation

Vulnerable adults

- National Health Service and Community Care Act 1990

- Carers (Recognition and Services) Act 1995

- Equality Act 2010

- Domestic Violence, Crime and Victims Act 2004

- Mental Capacity Act 2005

- Mental Health Act 1983, 2007 amendments

- Sexual Offences Act 2003

- National Health Service and Community Care Act 1990

- Homelessness Act 2002 (applies to adults and children)

Children

- Children Act 1989

- Children Act 2004

situation can be one of the biggest problems. This may be even more likely in people with severe mental illness and those with intellectual disability, who may be more dependent on family members to meet their care needs. Cognitive and communication difficulties, sensory impairment, thought disorder and other psychopathology may reduce the likelihood of victims disclosing the fear or existence of a forced marriage.

Both male and female victims may be subject to repeated sexual assault (including rape), domestic violence from their partner or extended family, or enforced domestic family service. Women may be disproportionately affected by sexual assaults. Additional consequences for people with intellectual disability and their spouses are shown in Box 4 .

The physical and emotional stresses within a sexual relationship, let alone any abuse, can have major consequences on mental health, giving rise to new illness or exacerbating an existing problem.

Rates of mental illness, including self-harm, suicide and eating disorders, have been found to

BOX 4 Additional consequences

- Abandonment: the spouse without a disability may reject the person with intellectual disability

- Unintended criminal offences by the spouse without disability (e.g. having a sexual relationship with a person without the capacity to consent to sex)

- Violence against spouse without disability should they seek to leave the marriage

- Financial exploitation of the person with intellectual disability by the non-disabled spouse

(After Clawson 2010: p. 14) 
be elevated in South East Asian communities within the UK, particularly in adolescent girls, and domestic abuse and marital relationships may be factors (Husain 2006). Between 2001 and 2009, the Southall Black Sisters (SBS) project supported or advised 3380 women who were seeking to escape domestic violence. Of these, 409 (12\%) were identified as having clear mental health problems and most (307) were of South Asian backgrounds. Of the 409 women with mental health problems, 299 were subject to domestic violence, 21 had been forced to marry, 13 had a diagnosed mental illness, 252 had contemplated suicide or self-harm and 73 had attempted it. These women were most likely to be aged 16-25 years. Over the years SBS has dealt with 18 suicides, and during the study period there were 8 deaths. Hanging and jumping were the most common methods (Siddiqui 2010). These findings highlight the potential impact of domestic abuse, including forced marriage, on mental health, although further research is required. Siddiqui $\&$ Patel's report contains a number of recommendations on services, therapeutic support, government policy and legal issues, as well as research.

There is little research evidence on the extent of mental health problems in the population of people forced into marriage; however, one might expect depression, anxiety-related states (including adjustment disorder) and features of post-traumatic stress disorder to be more prevalent. People with more severe intellectual disabilities may have the same mental health problems but display 'behaviourally equivalent' symptoms such as irritability instead of sadness in depression (Marston 1997). They might also exhibit specific disabilityrelated disorders as defined in the Royal College of Psychiatrists' (2001) diagnostic criteria for people with an intellectual disability. Comorbid pervasive developmental disorders such a childhood autism, Asperger syndrome or high-functioning autism could further increase vulnerability.

\section{Potential pitfalls for professionals}

Practitioners dealing with suspected or actual cases of forced marriage may be faced with a number of dilemmas. First, they may not feel confident in recognising the signs of people at risk of forced marriage. Practitioners may feel that they do not have a good understanding of the potential victim's culture or they may not question their understanding of forced marriage and be more accepting of what they are told is an 'arranged marriage'. They may fear being perceived as, at best, 'culturally insensitive' or at worst, racist. Practitioners may not have a clear understanding of their roles and responsibilities regarding safeguarding or question whether forced marriage is indeed a safeguarding issue. They may be ignorant of how best to reduce the risks to their patients, or worry about damaging relationships with local communities. What is clear, however, is that 'there is nothing honourable about abuse in the name of honour, and forced marriage demands protection not political correctness' (M. Sanghera, personal communication, 2011); it is still an abuse of human rights. Practitioners need to have a clear understanding of the differences between religious or cultural practice and see forced marriage as a form of abuse. Forced marriage then needs to be dealt with as abuse through the appropriate agencies. The following sections hope to address these issues, giving fictitious case scenarios and practical advice.

\section{Warning signs of forced marriage}

Uminia is seen in the accident and emergency department after an overdose of paracetamol. She had a previous attempt 6 months ago but never attended follow-up. At interview she reports increasing anxiety with the approach of her 18th birthday as her parents won't allow her out unaccompanied. She reports being 'promised to marry a family friend' in Pakistan as a child.

Impending or ongoing forced marriage may have an impact in a variety of areas, including health, engagement with services and police involvement. Likewise, identifying factors within the family history, such as siblings being forced to marry, may alert professionals to potential risk. Box 5 summarises general 'symptoms' or warning signs of a forced marriage.

In addition to these general warning signs, some potential indicators are more common for children or people with intellectual disability. They may talk about marriage, jewellery or wedding clothes. Wider family members may actively raise concerns about an impending marriage or a parent may approach professionals to sign a passport application or immigration forms. Children and young people may be taken out of their school or day centre placement without explanation and then taken out of the country. Changes in emotional state or displays of 'challenging behaviour' might also be present (Clawson 2010).

It is important to recognise that a professional whose suspicions are raised may have only one chance to prevent a forced marriage and its consequences. This 'one chance rule' forms the basis of statutory guidelines (Forced Marriage Unit 2010) on the processes that should be incorporated in the safeguarding systems of all regions following the Forced Marriage (Civil Protection) Act. Advice on how professionals can implement these processes 
BOX 5 General warning signs of forced marriage

\begin{tabular}{|c|c|c|}
\hline Family history & $\begin{array}{l}\text { - Withdrawal from education without home } \\
\text { schooling in place }\end{array}$ & - Removal from day services of a person with \\
\hline - Siblings reported missing & - Not allowed to attend extracurricular activities & Police involvement \\
\hline - Early marriage of siblings & - Sudden announcement of engagement to a & - Victim or other sibling within family reported \\
\hline - Self-harm of siblings & stranger & missing \\
\hline - Death of parent & - Sibling and cousin surveillance at school & - Domestic abuse, harassment or breaches of \\
\hline - Family disputes & - Prevention from going on to higher education & peace reported at family home \\
\hline - History of domestic abuse & Health & - Victim reported for offences (e.g. shoplifting) \\
\hline - Running away from home & - Accompanied to the doctor's or clinic & - Threats to kill, or attempts to kill or harm \\
\hline - Unreasonable restrictions (e.g. 'house arrest' or & - Self-harm & - Reports of other offences (e.g. kidnap, rape) \\
\hline financial constraints) & - Eating disorder & Employment \\
\hline - Threats to kill & - Attempted suicide & - Poor performance or attendance \\
\hline Education & - Depression & - Limited career choices/not allowed to work \\
\hline - Truancy or extended absence from education & - Isolation & - Unable to attend business trips or functions \\
\hline - Poor exam results & - Substance misuse & - Subject to excessive financial control \\
\hline - Request for extended leave of absence or failure & - Relapsing mental illness & - Accompanied to and from work \\
\hline to return from visits to country of origin & - Challenging behaviour & - Inflexible working arrangements \\
\hline - Decline in engagement, performance or & - Early/unwanted pregnancy & (Foreign and Commonwealth Office 2009. Reproduced \\
\hline behaviour & - Female genital mutilation & with permission of the Forced Marriage Unit) \\
\hline
\end{tabular}

is summarised in multi-agency guidelines (Foreign and Commonwealth Office 2009; Clawson 2010).

\section{What actions should be taken by front-line professionals?}

Deepak (16 years old) has a moderate intellectual disability and has been taken to the general practitioner (GP) by his father to get passport photos signed for a forthcoming trip to Bangladesh. While there, Deepak tells the GP he has been given wedding bangles and asks whether the GP has a nice wife. Summer term finishes in 4 weeks.

If in a consultation a front-line professional suspects a forced marriage has taken place or is about to take place, they should not pursue family involvement (counselling, mediation, arbitration, etc.). They should, as soon as possible, discuss the situation with their local trust and Social Services safeguarding teams, who should have a specialist in forced marriage with appropriate links to police and the Forced Marriage Unit (Fig. 1). Family liaison must only be pursued if agencies can be sure it will not place the individual at further risk and should only be used with great caution.

If there is concern that a person is imminently going overseas, the police and Social Services should be informed immediately, as there may be limited time to develop an adequate safety plan or seek protection (Foreign and Commonwealth Office 2009). In all cases it is important to gather as much information as might be relevant in supporting the person. Ideally, this should be done by trained specialists, but there may be occasions where the front-line professional will need to assist by creating opportunity and time for this to happen, for example insisting on seeing the person privately, staying with the person until advice and support is available, inviting them back to clinic for review if more time is required and it is safe to do so.

Where possible, information should include:

- a photocopy of their passport, details of the wider family and places they might stay overseas;

- information that only person would be aware of (if identification needs to be verified overseas), details of travel plans, names and addresses of close relatives remaining in the UK, a safe method of contact (e.g. secret mobile telephone, trusted friend);

- estimated return date and a written statement by the person explaining that they want the police, Social Services or third parties to act on their behalf should they not return by that date.

If an interpreter is needed, beware of using family members and be cautious of using local interpreting services in small, close-knit communities where inadvertent disclosures could happen. Consider using out-of-area interpreting services or in-house trust staff, ensuring they are aware of the risks and the need for absolute confidentiality. Even within 


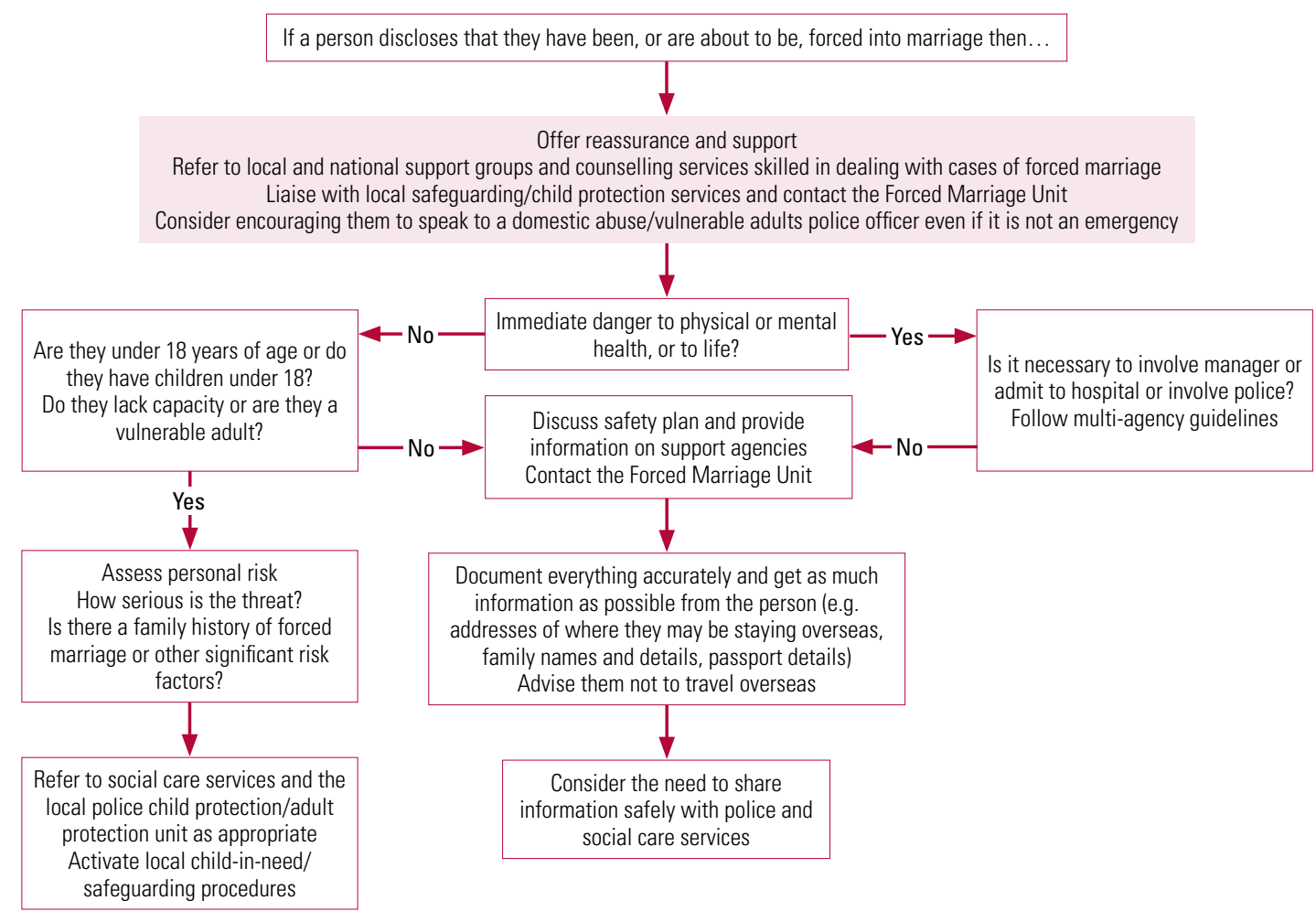

Decision tree for professionals suspecting forced marriage (Foreign and Commonwealth Office 2007: p. 27. Reproduced by kind permission of the Forced Marriage Unit).

the team information should be shared only on a need-to-know basis.

Javed (26 years old) was diagnosed with schizophrenia at the age of 20 and lives with his elderly parents. He has varied paranoid delusions and has had numerous admissions under the Mental Health Act 1983 for extreme aggression towards others. $\mathrm{He}$ takes clozapine and is currently under a community treatment order. His parents want permission for him to visit Pakistan. Two younger siblings live abroad following suspected forced marriages.

In some circumstances it would be justified, with the individual's consent, to admit them to hospital to provide immediate protection. Likewise, if someone at high risk were in a psychiatric hospital and about to be removed by relatives, professionals could seek to deny leave, initiating safeguarding procedures, while pursuing options either under the Mental Health Act or Deprivation of Liberty Safeguards (in England and Wales) and involving the Forced Marriage Unit and the trust's legal services. This would allow time for a more thorough assessment.

For people with intellectual disability or severe mental illness whose capacity and communication are affected, additional considerations will need to be made. It may be beneficial to involve a communications specialist and independent advocate (equivalent to the appropriate adult) in interviews. Capacity and consent issues may need to be more formally addressed.
Sometimes, families organising a marriage for a child or relative with intellectual disability do not think that they are doing wrong or do not understand that absence of capacity to consent would render it a forced marriage. Such situations can be complex and discussion with family members requires careful consideration to avoid putting the potential victim at increased risk of harm (Stobart 2009). In all cases, involve a child or adult protection specialist with expertise in forced marriage, and contact the police if the person is at risk of harm. Establish whether the person has capacity to consent to marriage, wants to be married and is of a legal age to marry. If not, explain to the family why the marriage should not happen, if this does not increase risk. Discussion might include legal implications and safeguarding concerns. If necessary, child or adult safeguarding procedures should be implemented. Professionals should never: ignore the matter; assume that the family will stop organising a marriage because of discussions with them; fail to obtain the victim's views; or lose contact with the family or victim (Clawson 2010).

When a person discloses that they have been or are about to be forced to marry, they may have limited options to avoid the situation. For example, should they remain within the family and to try to resolve the situation, or succumb to the family's 


\section{BOX 6 Managing disclosure regarding forced marriage}

\section{What to do}

- See the person immediately on their own (even if attending with others) in private

- Take issues seriously

- Assess risk and develop an appropriate safety plan

- Explain all options, recognising and respecting their wishes

- Take a detailed family history, including previous forced marriages, domestic abuse, family disputes, unreasonable restrictions and other mental health issues

- Advise against travel overseas

- Liaise with local safeguarding leads

- Seek information and support from the Forced Marriage Unit

- Refer (with consent) to local or national support groups

- Arrange future appointments, which may give a legitimate excuse for seeing professionals
What not to do

- Speak to the person in front of anyone else (particularly family)

- Treat allegations as merely a domestic issue and send the person back to the family home

- Neglect considering immediate protection issues

- Approach family members or those with influence in the community without expressed consent

- Contact the family in advance of enquiries by the police, Social Services or Forced Marriage Unit

- Share information outside child or adult protection protocols

- Breach confidentiality, except where necessary to ensure a person's safety

- Attempt to be a mediator

wishes, or flee the family and seek legal protection? Each of these choices has its own risks and consequences, but if there is concern about potential violence in the home, the first two are most risky. Box 6 highlights important things to do if a person discloses concerns about forced marriage.

\section{What if the person is already married?}

Abaan (aged 30) has mild intellectual disability, autism and bipolar disorder. Over 12 months he has shown an increase in aggressive behaviour at home and when he attends day services. Support staff have suspected that he was married in Egypt some years ago, a fact denied by his parents. He now tells his key worker that his wife and child are living with his family in the UK.

BOX 7 Useful organisations and guidelines

\section{Organisations}

General

- Forced Marriage Unit (www.fco.gov.uk/en/ travel-and-living-abroad/when-things-gowrong/forced-marriage)

- Southall Black Sisters

For people with intellectual disability

- Voice UK

- Ann Craft Trust

- Respond

- Honour Network (Karma Nirvana

\section{Guidelines}

- Multi-Agency Practice Guidelines: Handling Cases of Forced Marriage (Stobart 2009)

- The Right to Choose: Multi-Agency Statutory Guidance for Dealing with Forced Marriage (Forced Marriage Unit 2010)

- Forced Marriage and Learning Disabilities: Multi-Agency Practice Guidelines (Clawson 2010)
Amimbola (17 years old) has post-traumatic stress disorder. Her family allege that she was raped and she is currently pregnant. During a session with her psychologist she discloses that at 16 she was forced to marry a distant relative during a family holiday to Nigeria. Her husband is the father of her child and has recently applied for residency. He intends to visit the family home next week. She is scared about what will happen to her.

Sometimes cases of forced marriage only come to light after the event and when children have been born. These situations can be extremely complex to manage and safeguarding processes and child protection procedures may need to be started in close liaison with the Forced Marriage Unit. If offences are suspected, police involvement within these processes will be required. It is vital to assess each case individually and to make sure the needs of all parties, including spouse and children, are listened to and the risks assessed. The quality of the relationship as well as capacity and consent issues will be central to decisionmaking. Assumptions should never be made about the risks or otherwise of a situation, even if couples have been married for a long time.

\section{Conclusions}

Professionals working in mental health and learning disability services may see patients with exacerbations of or de novo mental health/ behavioural problems, who are under threat of or subject to a forced marriage, the consequences of which could be severe. Professionals may be in a unique position to intervene, but first they need to recognise the problem and know what to do. By improving their understanding, recognition and management of this often difficult-to-discuss area, clinicians can better meet the needs of this extremely vulnerable patient group.

There is limited research in this area and more needs to be done to quantify the problem within mental health and learning disability services, and better understand the implications for an individual's health and support needs. However, there are a number of useful practice guidelines and organisations available to advise professionals and support their patients (Box 7).

As well as direct advice and support, the Forced Marriage Unit provides a wealth of useful contacts and educational resources, including video and e-learning modules. We would suggest that awareness of forced marriage becomes an integral part of local training regarding the safeguarding of children and vulnerable adults, for all professionals working within mental health and learning disability services. We hope this article encourages further interest in this area. 


\section{References}

Clawson R, Vallance P (2010) Forced Marriage and Learning Disabilities: Multi-Agency Practice Guidelines. HM Government.

Disability Law Service (2009) Mental Capacity. DLS

Forced Marriage Unit (2010) The Right to Choose: Multi-Agency Statutory Guidance for Dealing with Forced Marriage. HM Government.

Gangoli G, Razak A, McCarry M (2006) Forced Marriage and Domestic Violence Among South Asian Communities in North East England. School for Policy Studies, University of Bristol, Northern Rock Foundation.

Gill AK (2011) Exploring the Viability of Creating a Specific Offence for Forced Marriage in England and Wales: Report on Findings. University of Roehampton.

Health Scotland (2008) Sexual Health and Relationships: A Review of Resources for People with Learning Disabilities. Health Scotland.

Hester M, Chantler K, Gangoli G, et al (2007) Forced Marriage: The Risk Factors and the Effect of Raising the Minimum Age for a Sponsor, and of Leave to Enter the UK as a Spouse or Fiancé(e). University of Bristol.

Home Office (2011) Consultation on forced marriage launched. Home Office.

Husain MI, Waheed W, Husain N (2006) Self-harm in British South Asian women: psychosocial correlates and strategies for prevention. Annals of General Psychiatry 5: 7.

Kazimirski A, Keogh P, Kumari V, et al (2009) Forced Marriage: Prevalence and Service Response. National Centre for Social Research.

KC \& NNC v City of Westminster v IC [2008] EWCA Civ 198.

Kelly G (2009) Sexuality and Intellectual Disability: Resources and Reading List. National Federation of Voluntary Bodies.

Khanum N (2008) Forced Marriage, Family Cohesion and Community Engagement: National Learning Through a Case Study of Luton. Equality in Diversity.

Marston G, Perry D, Roy A (1997) Manifestations of depression in people with intellectual disability. Journal of Intellectual Disability Research 41: $476-80$
Murphy GH (2003) Capacity to consent to sexual relationships in adults with learning disabilities. Journal of Family Planning and Reproductive Health Care 29: 148-9.

Number 10 (2011) Prime Minister's speech on immigration. HM Government.

O'Hara J, Hemmie M (2003) Parents with learning disabilities: a study of gender and cultural perspectives in East London. British Journal of Learning Disabilities 31: 18-24.

Peisah C, Brodaty H, Bridger M (2008) Abuse by marriage: the exploitation of mentally ill older people. International Journal of Geriatric Psychiatry 23: 883-8.

Ratnaike D (2007) I don't: escaping forced marriage. RCM Midwives 10: 312 .

Royal College of Psychiatrists (2001) DC-LD: Diagnostic Criteria for Psychiatric Disorders for use with Adults with Learning Disabilities/ Mental Retardation (Occasional Paper OP48). Royal College of Psychiatrists.

Samuel M (2008) Parents use forced marriage as care option for learning disabled. Community Care.

Sillifant K, O'Dwyer JM, Mindham RHS (1995) Some unusual legal issues. Psychiatric Bulletin 19: 117-8.

Siddiqui H, Patel M (2010) Safe and Sane: A Model of Intervention on Domestic Violence and Mental Health, Suicide and Self-harm Amongst Black and Minority Ethnic Women. Southall Black Sisters.

Singh MK (2011) Forced Marriage and Mental Health (Better Health Briefing Paper 24). Race Equality Foundation.

Stobart E (2007) Dealing with Cases of Forced Marriage: Practice Guidance for Health Professionals. FCO Services: publishing.

Stobart E (2009) Multi-Agency Practice Guidelines: Handling Cases of Forced Marriage. HM Government.

Women's Aid (2008) Forced marriage. Women's Aid (http://www. womensaid.org.uk/domestic_violence_topic.asp? section $=00010001002$ $20031 \&$ sectionTitle=Forced+marriage) .

\section{MCOs}

Select the single best option for each question stem

\section{Forced marriage:}

a occurs when one or both spouses do not or, through lack of capacity, cannot consent to the marriage

$\mathrm{b}$ is the same as an arranged marriage

c in the UK is most commonly seen in the African community

$d$ is classified as an abuse only when it affects people with an intellectual disability or severe mental illness

e is supported by most major religious faiths.

\section{As regards the forced marriage of people} with an intellectual disability in the UK:

a the vast majority of victims are women

b victims frequently express dissatisfaction with the marriage

c few cases are reported by a third party

d up to $80 \%$ of marriages occur in the UK

e at face value, motives behind the marriage may seem a positive attempt to protect the person.
3 As regards legislation on forced marriage:

a others can give consent to marriage on behalf of an adult who lacks capacity to consent

b 'forcing someone to marry' is a criminal offence in England, Wales, Northern Ireland and Scotland

c the Mental Capacity Act 2005 provides a useful framework for assessing capacity

$d$ only the individual under threat of a forced marriage can apply for a court protection order to prevent this happening

e offences under the Sexual Offences Act 2003 are unlikely to be committed.

4 The following is not a potential warning sign of forced marriage:

a failure to return from visits to country of origin

b decline in engagement and behaviour

c not allowed to attend extracurricular activities

d excellent exam results

e sibling surveillance.

\section{$\mathrm{MCO}$ answers}

1 a 2 e $3 \mathrm{c} \quad 4 \mathrm{~d} \quad 5 \mathrm{e}$ 